\title{
Garantia dos direitos humanos e o processo de ressocialização no sistema prisional
}

\author{
Guarantee of human rights and the process of resocialization in the prison system \\ Garantía de los derechos humanos y el proceso de resocialización en el sistema penitenciario
}

Recebido: 06/01/2022 | Revisado: 15/01/2022 | Aceito: 26/01/2022 | Publicado: 27/01/2022

Rosana Santos de Almeida

ORCID: https://orcid.org/0000-0001-8097-1074 Universidade Federal de Campina Grande, Brasil

E-mail: rosana.santos@estudante.ufcg.edu.br

Jonatas Claudio Farias Maciel

ORCID: https://orcid.org/0000-0002-4014-9622

Universidade Federal de Campina Grande, Brasil

E-mail: jonatasclaudiocz@gmail.com

Raquel Formiga de Medeiros ${ }^{1}$

ORCID: https://orcid.org/0000-0002-1198-5015 Universidad del Museo Social Argentino, Argentina

E-mail: raquelfdm@hotmail.com

Hugo Sarmento Gadelha ${ }^{2}$

ORCID: https://orcid.org/0000-0001-9414-0554 Universidad del Museo Social Argentino, Argentina

E-mail: hugoscurso@uol.com.br

Hiran Mendes Castro Filho ${ }^{3}$

ORCID: https://orcid.org/0000-0002-1418-159X Universidad del Museo Social Argentino, Argentina E-mail: hirancastro@gmail.com

Suzana Araújo dos Santos

ORCID: https://orcid.org/0000-0001-5955-9421 Universidade Federal de Campina Grande, Brasil

E-mail: suzana.santos2007@yahoo.com.br

Marcela da Silva Varejão

ORCID: https://orcid.org/0000-0003-1364-5492

Universidade Federal de Campina Grande, Brasil

E-mail: spark@velozmail.com

Agílio Tomaz Marques

ORCID: https://orcid.org/0000-0001-8364-5063

Universidade Federal de Campina Grande, Brasil

E-mail: agiliotomaz@hotmail.com

\begin{abstract}
Resumo
Os números do encarceramento no Brasil são preocupantes por causa do aumento excessivo da população carcerária, pois atualmente o Brasil vivencia uma situação de abandono no sistema prisional. Desta forma, o que deveria ser um instrumento de ressocialização, muitas vezes, funciona como escola do crime, devido à forma como é tratado principalmente pelo Estado, às condições precárias dos presídios são incapazes de ressocializar. O presente estudo se firma, na análise da realidade do apenado do Sistema Prisional e tem como objetivo, analisar a responsabilidade do Estado e da sociedade em relação à atual situação em que se encontra a população carcerária do Brasil, no tocante aos direitos humanos, e as garantias de ressocialização no cárcere. Nesse sentido foi empregada para a realização da pesquisa a metodologia utilizando o método de abordagem indutivo, e métodos de procedimento científico, histórico observacional qualitativo, o procedimento histórico observacional foi feito através das análises dos textos legais, e para os qualitativos foram utilizados nos dados do Sistema Integrado de Informações Penitenciárias, Infopen (2017). Conclui-se que a aplicação dos Direitos Humanos no sistema prisional e a garantia de processos ressocializadores são essenciais para a sociedade brasileira. Para tanto, é relevante a ampliação das discussões em seus muitos âmbitos, sejam eles governamentais, sociais, universitários e nos meios de comunicação.
\end{abstract}

Palavras-chave: População carcerária; Ressocialização; Sistema prisional.

\section{Abstract}

\footnotetext{
${ }^{1}$ Doutoranda pela Universidad del Museo Social Argentino.

${ }^{2}$ Doutorando pela Universidad del Museo Social Argentino.

${ }^{3}$ Doutorando pela Universidad del Museo Social Argentino.
} 
The numbers of incarceration in Brazil are worrying because of the excessive increase in the prison population, as Brazil currently experiences a situation of abandonment in the prison system. In this way, what should be an instrument of resocialization, often works as a school of crime, due to the way it is treated mainly by the State, the precarious conditions of prisons are unable to resocialize. The present study is based on the analysis of the reality of the prisoner in the Prison System and aims to analyze the responsibility of the State and society in relation to the current situation in which the prison population in Brazil finds itself, with regard to human rights, and guarantees of rehabilitation in prison. In this sense, the methodology was used to carry out the research, using the inductive approach method, and methods of scientific procedure, qualitative observational history, the observational historical procedure was done through the analysis of legal texts, and for the qualitative ones were used in the data of the Integrated Penitentiary Information System, Infopen (2017). It is concluded that the application of Human Rights in the prison system and the guarantee of resocializing processes are essential for Brazilian society. Therefore, it is relevant to broaden the discussions in its many spheres, be they governmental, social, university and in the media.

Keywords: Prison population; Resocialization; Prison system.

\section{Resumen}

Las cifras de encarcelamiento en Brasil son preocupantes por el aumento excesivo de la población carcelaria, ya que Brasil vive actualmente una situación de abandono en el sistema penitenciario. De esta forma, lo que debería ser un instrumento de resocialización, muchas veces funciona como una escuela del crimen, debido a la forma en que es tratado principalmente por el Estado, las precarias condiciones de las cárceles no logran resocializar. El presente estudio se basa en el análisis de la realidad del recluso en el Sistema Penitenciario y tiene como objetivo analizar la responsabilidad del Estado y de la sociedad en relación a la situación actual en que se encuentra la población carcelaria en Brasil, en lo que respecta a los derechos humanos y garantías de rehabilitación en prisión. En tal sentido se utilizó la metodología para realizar la investigación utilizando el método inductivo de enfoque, y métodos de procedimiento científico, cualitativo historia observacional, el procedimiento histórico observacional se hizo a través del análisis de textos legales, y para los cualitativos se utilizaron en los datos del Sistema Integrado de Información Penitenciaria, Infopen (2017). Se concluye que la aplicación de los Derechos Humanos en el sistema penitenciario y la garantía de procesos de resocialización son esenciales para la sociedad brasileña. Por lo tanto, es relevante ampliar las discusiones en sus múltiples ámbitos, sean estos gubernamentales, sociales, universitarios y mediáticos.

Palabras clave: Población reclusa; Resocialización; Sistema penitenciario.

\section{Introdução}

No Brasil, o ano de 2017, foi marcado por mais uma crise que há anos vem sendo anunciada, a crise do sistema penitenciário. Essa crise se dá principalmente pelo aumento excessivo da população carcerária, onde segundo os dados do Infopen, o Brasil tem a terceira maior população carcerária do mundo, atrás apenas dos Estados Unidos e da China, contribuindo, assim, para o aumento das condições sub-humanas em que se encontram os detentos.

É sabido que os números do encarceramento no Brasil são preocupantes, e nesse contexto o Código Penal esclarece que a pena deve ser proporcional ao delito que foi cometido e que sua função primária é a retribuição pelo crime cometido devendo está prevenir a ocorrência de outros delitos, contudo ela enseja obter a recuperação do presidiário através de mecanismos a serem idealizados no cárcere e alhures, com o objetivo da ressocialização e reinserção à sociedade.

De acordo com a Lei N ${ }^{\circ}$ 7.210, de 11 de julho de 1984, Lei de Execuções Penais (LEP), o presidiário é possuidor de diversas garantias que visam à segurança pessoal e pleno desenvolvimento da pena. Da alimentação e vestuário até se chegar ao auxílio jurídico e na possibilidade de trabalho remunerado, além de um ambiente adequado para o cumprimento da pena. $\mathrm{O}$ questionamento elencado na presente pesquisa, busca entender o sistema prisional em seus méritos e problemas.

Parte-se da seguinte questão: Como os Direitos Humanos está sendo aplicado no cárcere, e quais medidas podem ser usadas para a ressocialização? No entanto o cenário é completamente inverso, lugares insalubres, covil de insetos e da podridão, esta é a situação dos presídios. Portanto, é de grande mérito repensar toda a política carcerária da sua gestão aos recursos dispostos.

O indivíduo que retorna à sociedade após o cumprimento da sanção que lhe foi imposta não retorna só, mas traz consigo uma enorme quantidade de estigmas e rótulos que o perseguem e que o impedem de levar uma vida digna perante o 
meio social e o mercado de trabalho. Como se não bastasse, não é frequente a busca e interesse em políticas públicas direcionadas ao egresso por parte do Estado e da sociedade.

Não obstante, a sociedade não acolhe o egresso nem lhe oferece quaisquer condições de reabilitação. O Estado, na maioria das situações, também não dispõe de políticas públicas capazes de fornecer ao mesmo o apoio que necessita para manter-se longe da criminalidade.

Dessa forma o presente estudo se consolida na análise da realidade do apenado do Sistema Prisional e tem como objetivo, perquerir a responsabilidade do Estado e da sociedade em relação a atual situação em que se encontra a população carcerária do Brasil e do Nordeste, no tocante aos direitos humanos, e as garantias de ressocialização no cárcere, onde também procurou-se traçar o perfil da população carcerária região Nordeste, no que diz respeito idade, cor e escolaridade

Foi empregada para a realização da pesquisa o método de abordagem indutivo, e métodos de procedimento científico histórico observacional fundamentados na pesquisa bibliográfica, para a confecção do texto, a qual foi concretizada através da leitura, de textos, livros, artigos científicos e legislações, que foi complementado pelas análises dos textos legais, provenientes da pesquisa documental.

\section{Breve Análise do Sistema Prisional Brasileiro}

Na América Latina, no ano de 2016, o Brasil liderava o ranking dos países com as maiores populações carcerárias com 607 mil presos. Em seguida, aparece o México, com 255 mil, e a Colômbia, com 121 mil. Juntas, as nações reúnem 68,5\% do total de detentos no continente (Barbosa, 2019).

Concomitante o Brasil vivencia uma situação de abandono no sistema prisional, desta forma o que deveria ser um instrumento de ressocialização, muitas vezes, funciona como escola do crime, devido à forma como é tratado pelo Estado e pela sociedade (Assis, 2007).

Quanto ao papel do Estado, percebesse que o mesmo encontra serias dificuldades para cumprir o que está estabelecido, em diversos acordos legais, como na LEP, CF/88, Código Penal (CP), além das regras internacionais, como a Declaração Universal dos Direitos Humanos, a Declaração Americana de Direitos e Deveres do Homem e a Resolução da ONU que prevê as Regras Mínimas para o Tratamento do Preso (Assis, 2007).

Visto que está estabelecido na LEP, em seu art. $1^{\circ}$, que a execução penal que tem por objetivo efetivar as disposições de sentença ou decisão criminal e proporcionar condições para a harmônica integração social do condenado e do internado, ademais, a mesma norma prevê a classificação, assistência, educação e trabalho, aos apenados, o que visivelmente, não é cumprido na sua integralidade e ressocialização.

Observa-se que a (LEP) dispõem como instrumentos no Art. 41 diversos direitos como: alimentação suficiente e vestuário; atribuição de trabalho e sua remuneração; assistência material, à saúde, jurídica educacional, social e religiosa; entre outros. Dessa forma, o discurso jurídico penal brasileiro apresenta uma ideologia no qual, se utiliza das palavras prevenção, retribuição e ressocialização, contudo numa melhor compreensão sobre o sistema prisional.

Porém ressaltasse que apenas a palavra retribuição sendo a mais presente no contexto do sistema prisional é criticado por parte da sociedade, organizações nacionais e mesmo internacionais de Direitos Humanos, por ter deficiências que não proporcionam a ressocialização dos presos, acabando assim a aumentar o número de infratores e reincidentes.

\section{Direitos Humanos em uma Perspectiva para o Cárcere}

A construção e difusão dos Direitos Humanos são históricas e provém da luta da sociedade mundial por garantias que conduzissem o respeito aos direitos do homem em seus muitos aspectos como à vida, à liberdade e à honra. 
A abordagem desta temática deu-se em uma visão das garantias institucionais, fruto da Constituição Federal de 1988 (CF/88) dos tratados internacionais dos quais o Brasil é signatário visando entender, interpretar e refletir a atual situação dos direitos humanos e das garantias essenciais para aqueles que se encontram encarcerados. Ao mesmo tempo, é de grande relevância salvaguardar essa discussão, amparando-a no ideário de autores amplamente consagrados por sua credibilidade na disposição dos principais conceitos.

Nos últimos tempos, o Brasil tem vivenciado uma onda de violência sem precedentes fazendo com que surjam perguntas: "Onde está o problema que faz com que inúmeros crimes e delitos sejam praticados rotineiramente? O Estado não prende mais? A Lei brasileira é muito branda?" Examinando tais problemas de forma independente e imparcial, evidencia-se que a resolutividade não passa em princípio por esses três focos levantados.

Vale-se esclarecer que a pena, como ferramenta punitiva, é incapaz de reintroduzir o preso, depois de cumprida, à sociedade. Conforme dados do Infopen (2017) a população carcerária era de 726.354 mil presos para um total de apenas 423.242 mil vagas disponíveis. Nota-se, que os presídios se encontram em lotação máxima e as notícias que circulam, informam dos massacres e disputas entre as facções4 pelo poderio dentro dos presídios.

O massacre do Carandiru em 1992 em São Paulo chegou a vitimar 111 presidiários, sendo considerado um dos maiores da história. Além disso, problemas vivenciados no Presídio de Pedrinhas no Maranhão, Alcaçuz no Rio Grande do Norte e recentemente em Altamira Pará, apresentam o descontrole do sistema penitenciário.

\section{Direitos Humanos no Sistema Prisional}

A missão do Direito Penal será a proteção do bem jurídico com a garantia de punição e execução penal daquele que infligiu às regras dispostas. O Poder Judiciário é responsável pela ação penal, desde o processo inicial até os últimos recursos julgados. Com a condenação, se inicia a execução penal que ocorre no sistema penitenciário, sendo que essa deve seguir todos os quesitos que foram fixados no momento da condenação e o Poder Judiciário será o fiscal da execução da pena (SANTOS, 2019).

O Código Penal esclarece que a pena deve ser proporcional ao delito que foi cometido e que sua função primária é a retribuição pelo crime cometido devendo esta prevenir a ocorrência de outros delitos. Para a teoria mista, hoje praticada no Brasil, a pena deve ser retributiva, contudo ela enseja obter a recuperação do presidiário através de mecanismos a serem idealizados no cárcere, com o desejo da ressocialização e reinserção à sociedade.

No ordenamento jurídico brasileiro os direitos humanos estão resguardados na $\mathrm{CF} / 88$, em seu art. $5^{\circ}$, que é responsável por fazer acolher direitos e garantias advindas dos tratados internacionais dos quais o Brasil é signatário. Pode-se citar o Pacto de San José da Costa Rica6, que foi um marco dos Estados Americanos na luta e na defesa dos direitos humanos.

Deve-se, contudo, arrazoar que a validade destas normas será ratificada pelo Congresso Nacional que deve aprovar em dois turnos por 3/5 dos votos, para que equivalham a emendas constitucionais. Afirma a egrégia corte o Supremo Tribunal Federal (STF), que às normas não aprovadas em plenário pela Câmara dos Deputados e Senado Federal, podem adentrar pelo que dispõe o $\S 2^{\circ}$ do art. $5^{\circ}$ da $\mathrm{CF} / 88$.

$\mathrm{O}$ ordenamento jurídico garante aos presos uma série de direitos e garantias que devem ser observados no cumprimento da pena por parte do condenado. Assim explana Assis (2007, p. 4), referindo-se as garantias trazidas na lei: O espírito da lei é o de conferir uma série de direitos sociais ao condenado, visando assim possibilitar não apenas o seu isolamento e a retribuição ao mal por ele causado, mas também a preservação de uma parcela mínima de sua dignidade e a manutenção de indispensáveis relações sociais com o mundo extramuros.

A CF/88 em seu art. $1^{\circ}$, inciso III, destaca o princípio da dignidade humana, que em outros termos significa a base de todos os direitos fundamentais, orientando assim, o Estado Democrático de Direito. Para o espaço privado, o ser humano 
apresenta-se como indivíduo e no público como ser social. Assim, a dignidade humana significa e constitui-se como um valor individual, onde não se permite que seja sacrificado pelos coletivos (Costa \& Ferras, 2018).

O grande desígnio de todo o sistema penal é a recuperação do preso e garanti-lo o mínimo de condições para que ele possa atingir o tempo de sua pena, mas a realidade que se vê é um total desrespeito para com os direitos destes e uma ausência de recursos para melhoramento nas condições físicas dos presídios e na gestão técnica destes espaços.

A CF/88, assim dispõe em seu art. $5^{\circ}$, XLIX - "é assegurado aos presos o respeito à integridade física e moral". É notório saber que este princípio é totalmente desrespeitado dentro das celas. São verdadeiras atrocidades cometidas quando se colocam mais presos do que a capacidade, o conglomerado em um pequeno espaço gerará problemas sérios de saúde e comportamento, retirando os direitos básicos.

A política carcerária no Brasil, segue a linha da divisão de responsabilidades entre os Estados Membros e a própria União. Nos Estados os presídios são de responsabilidade das secretarias de segurança pública com os seus respectivos órgãos, sendo que o Governo Federal também dispõe de presídios federais em todo o território nacional, onde se encontram criminosos de alta periculosidade. Reis, (2017, p. 39), reflete a atual situação que vivência os presídios:

São diversas essas agressões, desde a ocorrência de homicídios, abusos sexuais, espancamentos e extorsões, sendo estas as práticas comuns por parte dos detentos que dentro do ambiente carcerário detêm um poder paralelo, que em função disso exercem um domínio sobre os demais presos, que acabam ficando subordinados a essa hierarquia interna, fazendo com que surja assim a "lei do mais forte" e a "lei do silêncio".

A resolutividade destes e outros assuntos passam por um diálogo, sociedade e Estado, pois é preciso encarar o problema do cárcere em seus diversos aspectos. Uma primeira perspectiva é a de maiores investimentos em políticas públicas sociais, que atinjam de frente o problema com o oferecimento de projetos e oficinas que levem a formação para o trabalho, maior distribuição de renda, possibilitando que não se falte o básico na mesa dessas famílias. Para o apenado é preciso que se garantam condições a fim de que a pena seja cumprida em respeito à legislação vigente, condições de saúde, educação, trabalho e práticas ressocializadoras.

A LEP assevera que o presidiário é possuidor de diversas garantias que visam à segurança pessoal e pleno desenvolvimento da pena. Da alimentação ao vestuário até se chegar ao auxílio jurídico e na possibilidade de trabalho remunerado, além de um ambiente adequado para o cumprimento da pena, é de grande valia pensar a política carcerária da sua gestão aos recursos dispostos, afim de a mesma cumprir seu papel.

\section{O processo de Ressocialização no Cárcere}

Uma das funções prementes da LEP é a garantia do cumprimento da pena e adoção de proposta ressocializadora que faça os apenados regressarem a sociedade recuperados. Além disso, se esclarece o conjunto de garantias, deveres e direitos que cada um terá e exercerá no âmbito prisional. A ressocialização significa reinserir na sociedade, através das práticas de trabalho, educação e atividades sociais aqueles que comentaram delitos.

Os dados dispostos pelo Infopen (2017), revelam que a taxa nacional de presidiários que estão tendo acesso à educação é de apenas $10.58 \%$ de 726.354 mil presos, ou seja, um valor de apenas 76.813 mil participam de atividades educativas. Observa-se a taxa de analfabetos, pessoas que por estarem em uma situação frágil socioeconomicamente, não tiveram a oportunidade de estudar e receberem a mínima educação necessária para que garantissem uma forma digna de sobrevivência.

Quando relatasse os dados de trabalho no cárcere, o abismo continua, a nível nacional apenas $17.54 \%$ estão em alguma atividade laboral, fato que preocupa quanto à ociosidade nestes espaços entendendo que a falta de uma ocupação faz com que o apenado vá planejar ações delituosas. 
Um dos principais problemas que afetam o processo de ressocialização é a gestão penitenciária, é cabível destacar que a administração da segurança pública10 é de competência dos Estados. A maior falha é a gestão destes ambientes, onde o chefe do executivo nomeia para os cargos de direção e afins, pessoas despreparadas sem capacitação inviabilizando e dificultando a gestão. Em seguida, há uma ausência de mecanismos tecnológicos que facilitassem o trabalho (Santos, 2018).

A realidade é que os presídios perderam suas funções fundamentais, onde se praticam atrocidades em seus muitos níveis, fazendo com que após o cumprimento da pena o apenado pior do que entrou devido a convivência com delinquentes de alta periculosidade. Para uma política carcerária efetiva é preciso entender o momento, no qual as facções criminosas tomaram o controle total de presídios, comandando os crimes nas cidades brasileiras.

Neste contexto a garantia para a ressocialização passa pela articulação de recursos financeiros para a área e consequentemente a inserção de projetos que envolvam o poder público e iniciativa privada.

A realização de capacitações contínuas e de um processo seletivo para os cargos da gestão penitenciária promoverá a reorganização deste sistema. É apropriado que se aproveitem os meios tecnológicos para o controle no cárcere, na gestão financeira e execução penal, pois o controle interno seria feito com maior celeridade.

\section{Considerações Finais}

A presente pesquisa analisou o sistema prisional brasileiro à luz dos dispositivos legais da legislação nacional e internacional, inquirindo-se como se concebe a aplicação dos Direitos Humanos Fundamentais nos espaços prisionais. O aprisionamento em massa não consiste em um problema apenas do Brasil, mas outros países possuem taxas de encarceramentos exorbitantes.

Os órgãos nacionais demonstram dados que revelam as peculiaridades dessa população presidiária que em sua grande maioria envolve-se cedo com a criminalidade. Dado exposto, a faixa etária de jovens presos em idade produtiva é relevante, o problema é mais social do que mesmo carcerário. A não oferta de ensino na infância apresenta os altos índices de analfabetismo nestes locais, cabendo uma reflexão crítica.

Em vista dos argumentos apresentados é acurada a necessidade de ressocialização, para que se conceda a oportunidade ao apenado de regressar a sociedade, fora do crime. Porém, este direito garantido na CF/88, CP, LEP, não é observado, fato que preocupa. O começo para que haja atividades ressocializadoras, se encontra na gestão prisional, devendo está ser tratada como ponto crucial de modificação dos presídios, é de bom alvitre que se tenham maiores investimentos em tecnologias, parcerias privadas e eficiência gestacional que pode ser alcançada com cursos preparatórios para os cargos a serem ocupados na gestão.

Conclui-se que a aplicação dos Direitos Humanos no sistema prisional e a garantia de processos ressocializadores são essenciais para a sociedade brasileira. Para tanto, é relevante a ampliação das discussões em seus muitos âmbitos, sejam eles governamentais, sociais, universitários e nos meios de comunicação. Dados são dispostos rotineiramente e precisam ser analisados, questionados e abalizados para que se consiga fazer com o que o cárcere cumpra seu papel, respeitando a lei, a ressocialização seja efetivada e as políticas públicas de inclusão possam chegar para todos.

\section{Referências}

Assis, R. D. de. (2007). A realidade atual do sistema penitenciário Brasileiro. Artigo Científico. http://br.monografias.com/trabalhos908/a-realidade-atual/arealidade atual.shtml.

Barbosa, R. (2019). População carcerária na América Latina dobra em 19 anos. https://www.poder360.com.br/internacional/populacao-carceraria-na-americalatina-dobra-em-19-anos

Brasil. (1988). Constituição da República Federativa do Brasil, 5 de outubro de 1988. http://www.planalto.gov.br/ccivil_03/Constituicao/Constituicao.htm. 
Research, Society and Development, v. 11, n. 2, e34911225443, 2021

(CC BY 4.0) | ISSN 2525-3409 | DOI: http://dx.doi.org/10.33448/rsd-v11i2.25443

Brasil. (1940). Código Penal. Decreto-Lei No 2848, 7 de dezembro de 1940. http://www.planalto.gov.br/ccivil_03/Decreto-Lei/Del2848.htm.

Brasil. (1984). Lei de Execução Penal, Lei No 7210, 11 de julho de 1984. http://www.planalto.gov.br/ccivil_03/LEIS/L7210.htm.

Brasil. (1992). Promulga a Convenção Americana sobre Direitos Humanos. Decreto $\mathrm{N}^{\circ} \quad 678,6$ de novembro de 1992. http://www.planalto.gov.br/ccivil_03/decreto/D0678.htm.

Brasil. Ministério da Justiça. Departamento Penitenciário Nacional - Sistema Integrado de Informação Penitenciária (Infopen). http://dados.mj.gov.br/dataset/infopen-levantamento-nacional-de-informacoes-penitenciarias

Costa, M., \& Ferras, A. C. da C. (2018). Constituição Federal interpretada: artigo por artigo, parágrafo por parágrafo. 9. ed. Barueri.

Levantamento Nacional de Informações Penitenciárias INFOPEN Mulheres - junho2014. (2015). Ministério da Justiça - Departamento Penitenciário Nacional, Brasília, DF. http://www.justica.gov.br/noticias/estudotracaperfidapopulacaopenitenciaria-feminina-no-brasil/relatorio-infopen-mulheres.pdf.

Levantamento Nacional de Informações Penitenciárias - Infopen, Junho /2017. (2017). Dados referentes a dezembro de 2016. http://depen.gov.br/DEPEN/noticias1/noticias/infopenlevantamentonacionaldeinformacoespenitenciarias2016/relatorio_2016_22111.pdf.

Machado, N. O., \& Guimarães, I. S. (2014). A realidade do Sistema prisional brasileiro e o princípio da dignidade da pessoa humana. Revista Eletrônica de Iniciação Científica. Itajaí: v. 5, 566-581.

Marques, J. et al. (2013). A Realidade do Sistema Prisional no Brasil: Um dilema entre as penas e os direitos humanos Trabalho apresentado no V Seminário da Pós Graduação em Ciências Sociais: Cultura, Desigualdade e Desenvolvimento - realizado entre os dias 02, 03 e 04 de dezembro de 2015, em Cachoeira, BA, Brasil. MORAES, Alexandre de. Direito Constitucional. São Paulo: Atlas.

Reis, T. M. dos. (2017). Direitos humanos no sistema penitenciário. 2017. p. 47. Trabalho de conclusão de curso - Bacharel em Direito. Centro Universitário do Cerrado, Patrocínio MG.

Santos, V. É. da S. (2018). O papel do gestor de presídios: Uma análise, acerca da formação, prática e eficácia da gerência prisional. 2018. Trabalho de conclusão de curso- Especialização em gestão pública modalidade à distância - Instituto Federal de Educação, Ciência e Tecnologia da Paraíba, Itaporanga PB.

Santos, V. É. da S. (2019). Estabelecimentos prisionais agrícolas no Brasil: Uma ferramenta de ressocialização, gestão pública sustentável e fomento ao setor agroindustrial. 2019. Dissertação para obtenção do título de Mestre, programa de Pós-Graduação em Sistemas Agroindustriais - Universidade Federal de Campina Grande, Pombal PB. 